\title{
Efficiency Improvement in Dye-Sensitized Solar Cells by Modify Titanium Dioxide Formation on Supercritical Carbon Dioxide Fluid Synchronous Dyeing
}

\author{
Shen-Kung Liao ${ }^{*}$, Jin-yu Ruan ${ }^{1}$, Chie-Hao Chao ${ }^{1}$,Chih-Hsun Liao ${ }^{2}$ \\ ${ }^{1}$ Department of Fiber and Composite Materials, Feng Chia University, Taichung, Taiwan \\ ${ }^{2} \mathrm{SCH}$ Electronics Cooperative Limited, Taiwan \\ Corresponding Author’s e-mail : skliao@ fcu.edu.tw
}

\section{ABSTRACT}

\section{Article Info}

Volume 8, Issue 4

Page Number : 626-636

\section{Publication Issue}

July-August-2021

\section{Article History}

Accepted : 12 Aug 2021

Published : 22 Aug 2021
In this study, the dye sensitized solar cells (DSSC) were assembled by using natural dyes extracted from roselle and red phoenix as sensitizer coated fluorinedoped tin dioxide substrate (FTO) plate used a counter electrode for nanocrystalline $\mathrm{TiO}_{2}$. We investigated the formation of modified titanium dioxide on dye-sensitized solar cells by simultaneous dyeing with supercritical carbon dioxide fluid. The photoelectrode is made of compact layer and scattering layer. Supercritical carbon dioxide fluid extracted natural dyestuff and synchronous dyed photoelectric. The photoelectric conversion efficiency is the best at the dyeing parameters of 3000 psi, $50{ }^{\circ} \mathrm{C}$, and 30 minutes. Experimental results show that adding a scattering layer to the compact layer can improve the conversion efficiency. SEM can observe that the polyethylene glycol-added scattering layer has more pore structures in which improves the electrode's ability to capture sunlight. The conversion efficiency of $0.13 \%$ can be obtained by using 9:1 mixed dyes of anthocyanin and chlorophyll. The photoelectric conversion efficiency with the P25/R-type/PEG scattering layer is about 30\% higher than that of a single compact layer. Finally the paper proposes a schematic diagram of the dye-sensitized solar cell.

Keywords : Synchronous Dyeing, Dye-sensitized, Supercritical fluid, Anthocyanins, Chlorophyll, DSSC.

\section{INTRODUCTION}

Dye-sensitized solar cells (DSSCs) are the process of sensitizing the wavelength of visible light into electrical energy. DSSCs have the advantages of environmental protection and low manufacturing costs, as well as their added value in the product and commercial application, so it has always been a topic of great interest to related researchers. The performance of the DSSCs mainly depends on a dye used as sensitizer. The absorption spectrum of the dye and the titanium dioxide photoelectrode of formation 
are important that determining the conversion efficiency of DSSCs, as shown figure 1 model of dye sensitized solar cells.[1-3] The first DSSCs was designed in 1976 in Japan by Tsubomura, who found that porous zinc oxide of photoelectric, but the research are neglected because low efficiency. Until 1991 in Switzerland, Gratzel used nanostructures as photoelectric to adsorbing the dye.[4,5] The nanostructures DSSCs the efficiency higher than before and the manufacturing cost are lower than traditional silicon solar cells.

Because titanium dioxide usually only absorbs ultraviolet light, it is necessary to effectively use sunlight in dye-sensitized solar cells. In addition to modifying the titanium dioxide itself, another method is to immerse the dye molecules on the metal oxide by soaking in a chemical solution. Judy N. Hart et al. showed that the barrier layer can improve the conversion efficiency of the battery. The more barrier layers, the higher the battery efficiency. In 2006, Hore $\mathrm{S}$ et al. pointed out that adding a scattering layer can effectively improve the conversion efficiency of the battery. In the study up to $80 \%$ increase in current density was observed due to inclusion of scattering layers. In 2010, Jinho Chae et al. combined nano-scale gallium with titanium dioxide to make a photoelectrode. The results show that the conversion efficiency of the photoelectrode combined with gallium is about $4.57 \%$ higher than that of the pure titanium dioxide photoelectrode.[6-8] In 2012 Niu Huang et al. used titanium tetrachloride to treat zinc oxide photoelectrode. The photoelectrode can improve the adsorption of dyes and form a good electron transport film with a conversion efficiency of 6.39\%. In the same year, Curtiss S et al. used the RFsputtering method and the sol-gel method to prepare the compact layer, which can improve the contact between the conductive film and the electrode, and the conversion efficiency of the two methods were increased by about $18.9 \%$ and $25.3 \%$, respectively. $[9,10]$
Gases and liquids become supercritical fluids when they are compressed and heated above their critical pressure and temperature. In this state these supercritical fluids exhibit properties between those of typical gases and liquids. Compared with liquids, the density and viscosity of supercritical fluids are lower, but diffusion in these materials is greater. Hence, supercritical fluids are widely used in chemical extraction, reactions, polymerization, chromatography, and impregnation of desired additives into various materials. Austrian scholar Marr and German scholar Werner reviewed related literature publication and technical conditions of using supercritical fluid in extraction processing, and proposed that the phase behavior of supercritical fluid dissolved solute under different PVT (P: pressure, V: volume, T: temperature) conditions is the key factor influencing the extraction effect. They argued that the important factors, such as phase behavior and solubility of solute in supercritical fluid, could be estimated by using the equation of state.[11-13] In this paper, we use supercritical carbon dioxide dyeing technology instead of impregnation as a facile process for fabrication dye-sensitized solar cells using anthocyanin/chlorophyll into titanium dioxide as the photoelectrode. The DSSCs photoelectrode is currently impregnation and require for up to twenty hours or more, so the adsorption isn't satisfactory by impregnation. We use the supercritical $\mathrm{CO}_{2}$ fluid viscosity and diffusion, the adsorption of titanium dioxide could decrease the time to dyed nanocrystalline titanium dioxide photo-electrodes and avoiding prolonged exposure to photosensitive dye into the air. Thus we expect supercritical fluid dyeing way improves efficiency of DSSCs and achieve zero pollution. 


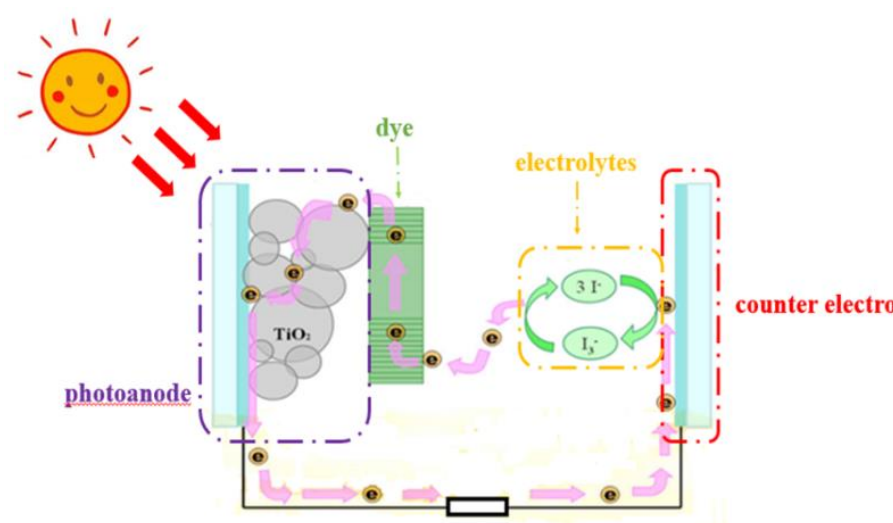

Figure 1. Schematic diagram of dye sensitized solar cells

\section{EXPERIMENTAL}

\subsection{Titanium dioxide compact layer}

In this experiment, titanium isopropoxide, ethanol, nitric acid and deionized water were used in molar ratios of titanium isopropoxide: ethanol: nitric acid: deionized water by1:15:3:2, stirred at room temperature for 24 hours to prepare a sol gel precursor firstly. Add $0.1 \mathrm{~mL}$ of acetone as a dispersant to uniformly disperse the resulting sol-gel. After the reaction is completed, the sol-gel solution is spin-coated on FTO to form a titanium dioxide film, which is passed through a vacuum oven Drying at $70{ }^{\circ} \mathrm{C}$ and then sintering at $500{ }^{\circ} \mathrm{C}$ in a high-temperature furnace to obtain a compact layer of titanium dioxide. Second Degussa P25 titanium dioxide, ethanol and deionized water were made into titanium dioxide slurry with a weight percentage of $1: 2: 2$, and $0.1 \mathrm{~mL}$ of acetone was added as a dispersant. The titanium dioxide slurry is stirred for 12 hours with an electromagnetic heating stirrer, and then spin-coated on the FTO substrate to form a thin film. After the thin film is dried, it is sintered in a high-temperature furnace to obtain the battery compact layer.

\subsection{Light scattering layer}

Use commercial titanium dioxide, polyethylene glycol, ethanol and deionized water at a weight percentage of 1:1:3:3 and add $0.1 \mathrm{~mL}$ of acetone to prepare a titanium dioxide slurry, which uses Rutile-type and Degussa P25 respectively. Two kinds of titanium dioxide R-type and Degussa P25 were obtained from Echo Chemical Co, Taiwan. As a material for preparing the slurry, the Rutile-type is a white powder with a purity of $99.9 \%$ in Titanium(IV) oxide rutile form and a particle size range of 200-400 nm. The other Degussa P25 is a white powder with a particle size of $21 \mathrm{~nm}$ of Titanium(IV) oxide powder. The titanium dioxide slurry was stirred with an electromagnetic heating stirrer for 12 hours, spincoated on the dye adsorption layer, dried and sintered at a high temperature to obtain the light scattering layer of the electrode. The flow chart is shown in Figure 2. Four scattering layers of R-type, R-type/PEG, P25/PEG, and P25/R-type/PEG are produced according to different matching parameters.

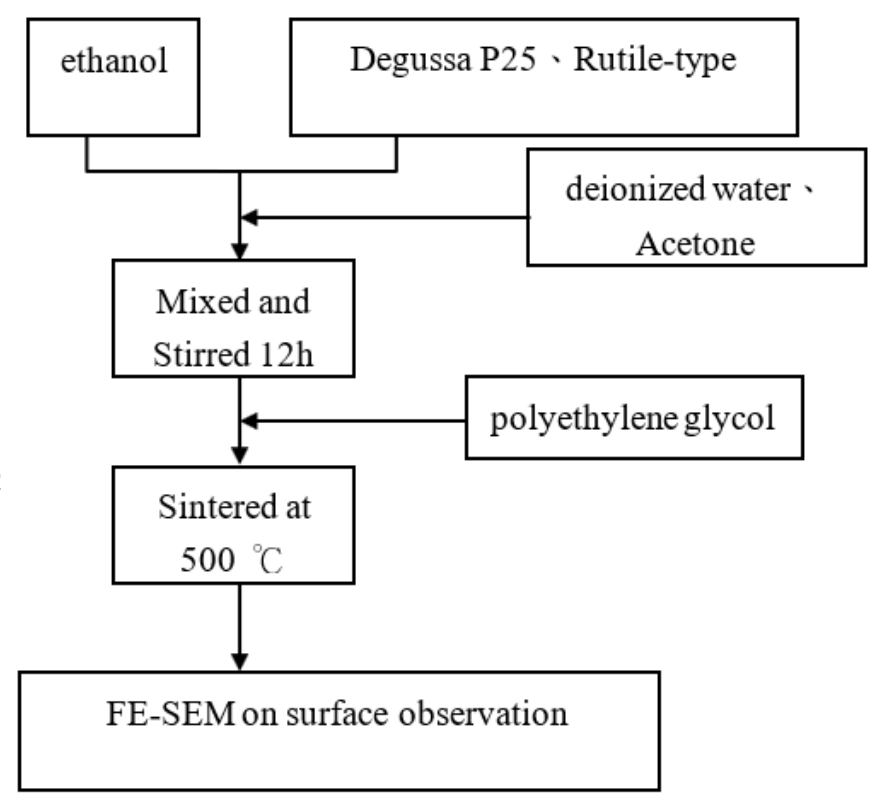

Figure 2. Flow chart of light scattering layer production

\subsection{Dye extraction and simultaneous dyeing}

The development of solar green renewable energy, and has many advantages are great attention.[14,15] Dye-sensitized solar cells use cheap and easy-toobtain glass as the base material and are coated with conductive materials, combined with dye molecules and nano-level metal oxide semiconductor powder, which can absorb sunlight and convert it into electrical energy. The photoelectrode is prepared by using supercritical carbon dioxide fluid to utilize its 
high density and high diffusivity to achieve highefficiency dye extraction and photoelectrode simultaneous dyeing to shorten the manufacturing process. The dye-sensitized solar cell still maintains the original or even better photoelectric conversion efficiency.

Chlorophyll is a fat-soluble natural pigment that is widely present in plant leaves in nature. Its basic structure is mainly composed of four pyrroles, forming a macrocyclic compound with conjugated double bonds called porphyrin. It is called pyrrolidin. Chlorophyll is a magnesium porphyrin derivative. It consists of four nitrogen atoms chelating a magnesium ion and has the function of absorbing light energy. The porphyrin ring has a special long chain of carbon and hydrogen, one of which is a long chain of phytol, which is called phytol. Figure 3 shows the structure of chlorophyll. Chlorophyll is used as a sensitizer for dye-sensitized solar cells, and its bonding method is shown in Figure 4.[16] Diagram of titanium dioxide and anthocyanins bonding scheme was shown and our early studies too. [3,17]

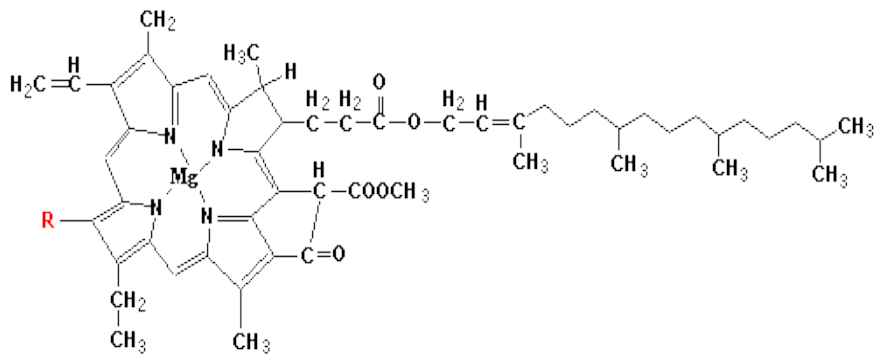

Figure 3. Structure of chlorophyll

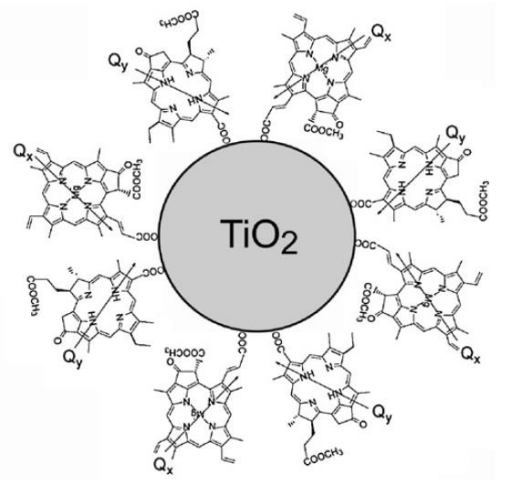

Figure 4. Diagram of titanium dioxide and chlorophyll bonding scheme
Using titanium dioxide, polyethylene glycol, ethanol and deionized water at a weight percentage of 1: 1: 3 : 3 and adding $0.1 \mathrm{~mL}$ of acetylacetone to form titanium dioxide slurry, in this case two titanium dioxide R-type and Degussa P25 were used as the material for the preparation of the slurry. The titanium dioxide slurry was stirred for 12 hours with an electromagnetic heating stirrer, spin coating on the compact layer after drying and high temperature sintering to get the electrode light scattering layer. The R-type, R-type / PEG, P25 / PEG, P25 / R-type / PEG four kinds of scattering layers were prepared according to different parameters.

\section{RESULT AND DISCUSSION}

\subsection{Particle Size analyses}

The particle size analysis of sol-gel titanium dioxide is presented in Figure 5. The particles are distributed from $3 \mathrm{~nm}$ to $55 \mathrm{~nm}$, mainly in the range of 3.79-6.80 $\mathrm{nm}$. The Table 1 is analysis volume results of sol-gel titanium dioxide, the average particle size of the titanium dioxide particles is $6.3 \mathrm{~nm}$, the particle size is less than $10 \mathrm{~nm}$, but the volume percentage is below $2 \%$. The size of the sol-gel titanium dioxide particles is uniform and the particle size difference is not significant.

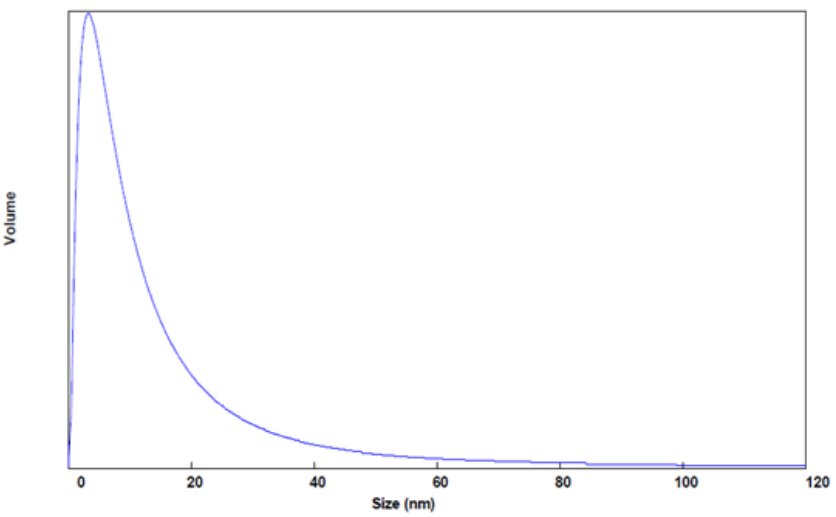

Figure 5. The particle size distribution of sol-gel titanium dioxide 
Table 1. The particle size of sol - gel titanium dioxide from volume results summary

\begin{tabular}{|c|c|c|c|c|c|}
\hline \multirow{4}{*}{ Angle } & \multicolumn{5}{|c|}{ Calculated Results } \\
\cline { 2 - 6 } & $\begin{array}{c}\text { Size } \\
(\mathrm{nm})\end{array}$ & $\begin{array}{c}\% \text { amt } \\
(\mathrm{nm})\end{array}$ & $\begin{array}{c}\text { Std.Dev } \\
(\mathrm{nm})\end{array}$ & $\begin{array}{c}\text { Mean } \\
\text { Size } \\
(\mathrm{nm})\end{array}$ & $\begin{array}{c}\% \\
\text { Dust }\end{array}$ \\
\hline $90.0^{\circ}$ & 4.4 & 87.25 & 0.8 & 6.3 & 0.000 \\
\cline { 2 - 6 } & 19.5 & 12.75 & 7.6 & & \\
\hline
\end{tabular}

\subsection{Powder XRD analysis}

The crystalline phase of $\mathrm{TiO} 2$ nanoparticles were analyzed by X-ray diffraction (XRD type MXP3) measurement using target material: $\mathrm{Cu}$, wavelength: $1.5405 \mathrm{~nm}$, filter: $\mathrm{Ni}$, voltage: $30 \mathrm{KV}$, current $20 \mathrm{~mA}$, scanning angle: $5 \circ-70 \circ$, analyze the crystal form and crystal strength of the titanium dioxide film to determine the crystal form of the sample. Figure 6 shows the powder XRD pattern of as- prepared TiO2 nano-particles and the presence of sharp diffraction peaks in the XRD confirm that products are highly crystalline. Shown on Figure 6(a), XRD spectra of titanium dioxide compact layer that a strong diffraction peak at $2 \theta=25.045$ oand the secondary diffraction peaks at $2 \theta=$ $36.083 \circ, 39.189 \circ, 41.239 \circ, 44.057 \circ, 54.321 \circ, 56.632$ oand 69.007 owhich is the diffraction peak of rutile(110). In addition, a smaller diffraction peak appears at $2 \theta=$ $27.215^{\circ}$,which is the main diffraction peak of rutile(110), and the secondary diffraction peak at $2 \theta=$ $35.925^{\circ}$ is also consistent with the reference to the characteristics of rutile titanium dioxide peak. The peaks of anatase(101) and rutile(110) appear in the XRD pattern. The titanium dioxide produced in this experiment is mainly composed of anatase phase and trace rutile phase.

Degussa P25 is composed of anatase phase and rutile phase composed of titanium dioxide, the weight ratio of 71 to 29, as shown in Figure 6(b), there is a strong diffraction peak at $2 \theta=25.250 \circ$, and followed by $2 \theta=$ $38.471 \circ, 48.010 \circ, 53.917 \circ, 55.024 \circ$ and $62.702 \circ$ which is the diffraction peak of anatase(101). In addition, the main diffraction peak of rutile(110) is shown at $2 \theta=$ $27.410 \circ$,followed by $2 \theta=36.046 \circ$ and $68.905^{\circ}$.It can be proved to the experiment used P25 titanium dioxide for the anatase phase and a small amount of rutile phase.

R-type titanium dioxide is almost composed of rutile phase, as shown in Figure. $\mathrm{X}(\mathrm{c})$, that a strong diffraction peak at $2 \theta=27.410 \circ$, which is the main diffraction peak of rutile(110). The secondary diffraction peaks at $2 \theta$ = $36.083 \circ, 39.189 \circ, 41.239 \circ, 44.057 \circ, 54.321 \circ, 56.632 \circ a n d$ 69.007oare in line with the rutile phase characteristic peaks mentioned in the literature.[18]
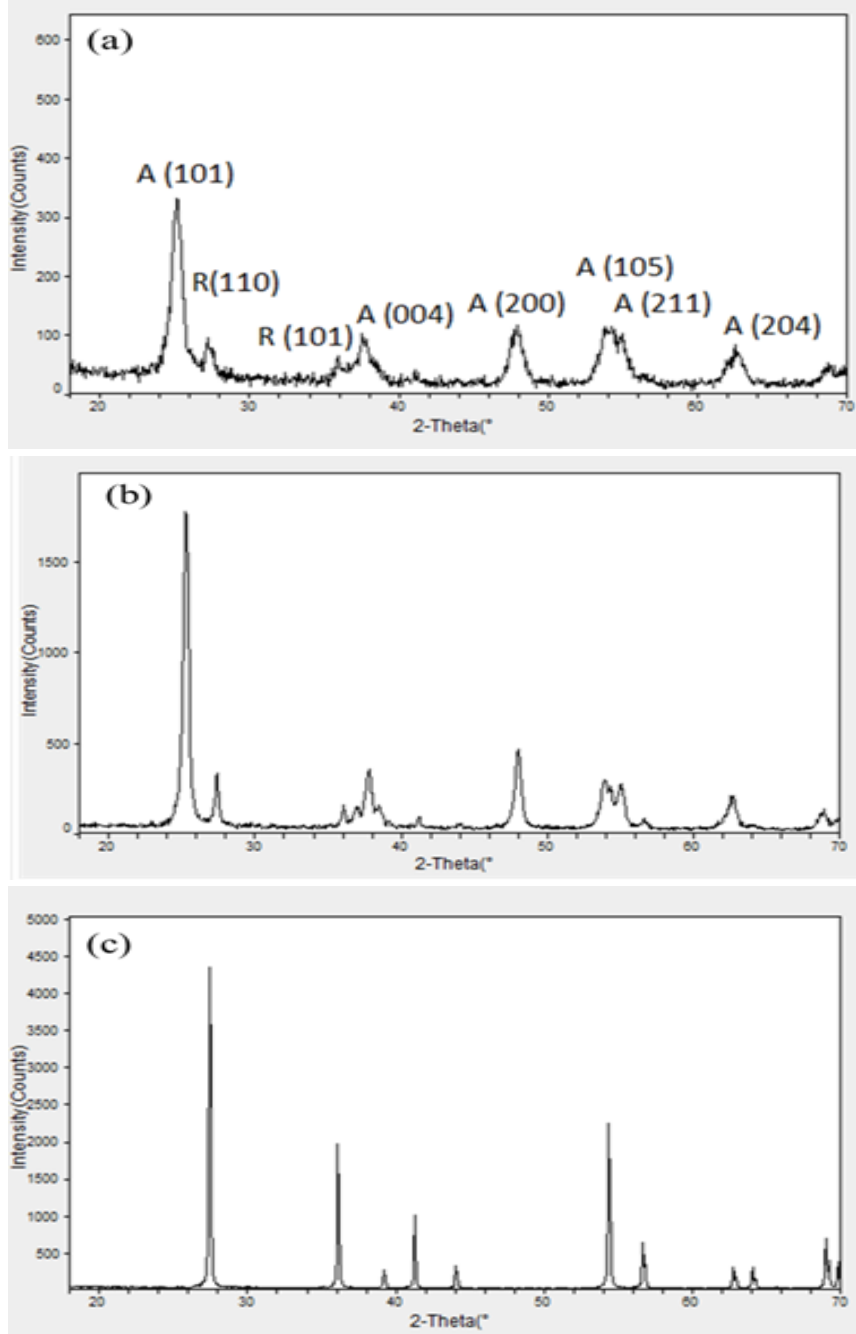

Figure 6. XRD spectra of (a) Titanium dioxide compact layer (b) P25 Titanium dioxide (c) R-type Titanium dioxide 


\subsection{Scanning Electron Microscope analysis of the electrode surface}

In the study we investigated the modified of photoelectrode was made with compact layer and scattering layer. In this part, analysis of the electrode surface from scanning electron microscope analysis.

(1) Compact layer: The SEM of the sol-gel titanium dioxide compact layer is shown in Figure 7. These micrographs indicate that the surface of titanium dioxide particle size is uniform. The particle size of the compact layer after high temperature sintering is about $5 \mathrm{~nm}$, and a few titanium dioxide particles larger than $5 \mathrm{~nm}$ are also smaller than $10 \mathrm{~nm}$, which is consistent with the results of the aforementioned particle analysis, and the structure is shown in Figure 8 which is schematic diagram of titanium dioxide compact layer.

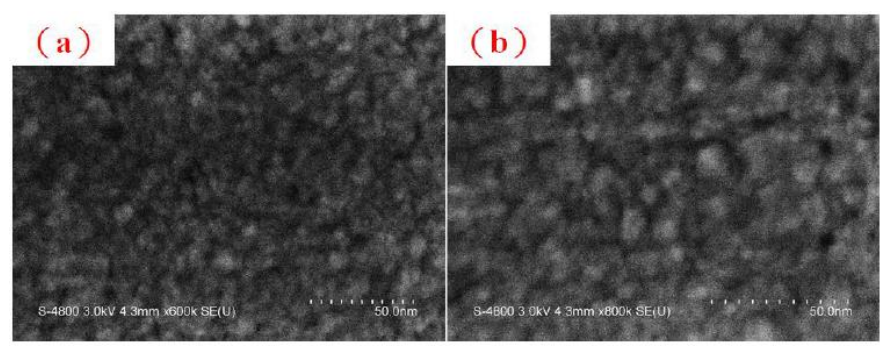

Figure 7. Scanning electron micrograph (SEM) of the sol-gel titanium dioxide compact layer. Magnification at (a) $600 \mathrm{k}$ (b) $800 \mathrm{k}$

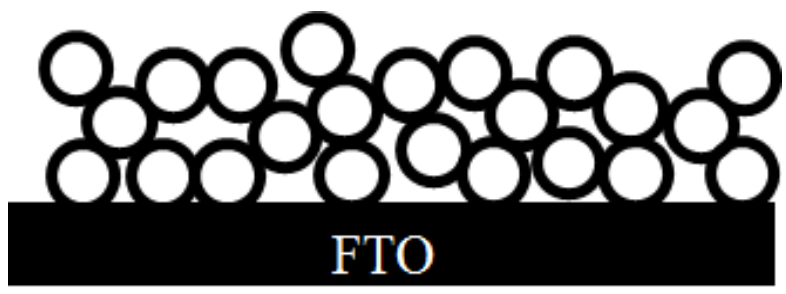

Figure 8. Schematic diagram of titanium dioxide compact layer

In order to increase the thickness of the compact layer, it is expected that more photoelectric dyes can be adsorbed, so this experiment increases the number of coatings. Figure 9 shows the compact layer repeated one to four times. Obviously, the surface of the coated single compact layer is completely smooth with only a few parts producing small cracks. The surface of the double-layer compact layer is severely cracked and split into small uniform pieces. The surface of the compact layer with more than three layers is split into massive titanium dioxide of different sizes, and even peeling. According to the experimental results, it could be found that as the number of compact layers increases the cracks on the surface become more obvious. And the peeled off massive titanium dioxide will destroy the overall structure of the compact layer. Unfortunately these cannot improve the conversion efficiency of the photovoltaic cell when we repeated coating of the compact layer. Even greatly reduce its conversion efficiency.

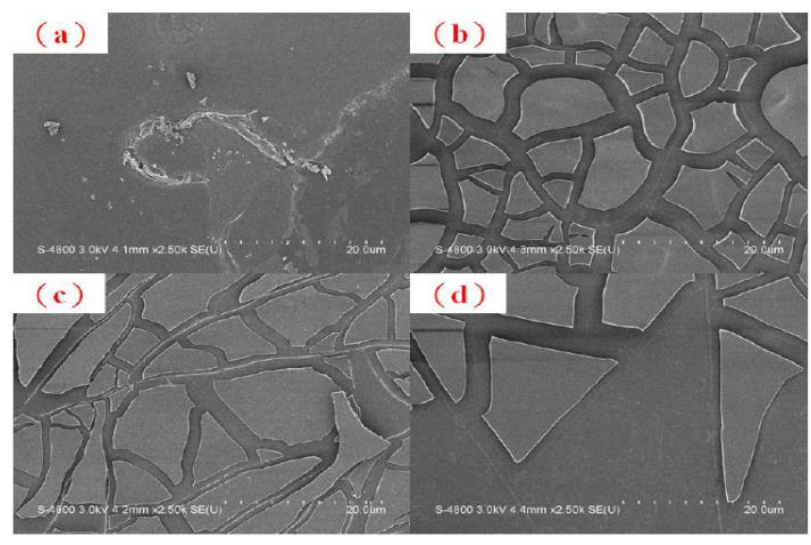

Figure 9. Scanning electron micrograph (SEM) of the compact layers (a) monolayer (b) bilayer (c) three layers (d) four layers. Magnification at $2.5 \mathrm{k}$.

(2) Scattering layer: The SEM of the R-type, Rtype/PEG, P25/PEG, P25/R-type/PEG four kinds of scattering layers in Figure 10. As shown in Figure 10(a), the scattering layers of R-type found extensive aggregation of titanium dioxide which have void around $500 \mathrm{~nm}$. The void structure leads to difficulty of electronic transmission and reduce the DSSCs conversion efficiency. Figure 10(b) shows the scattering layers of R-type/PEG, which have void 
around $100 \mathrm{~nm}$. In the process of adding polyethylene glycol, it leads titanium dioxide to reducing aggregated. Figure 10(c) shows the scattering layers of P25/PEG. The particle size of P25 titanium dioxide is smaller than R-type. Therefore, photoelectrodes of P25/PEG scattering layers have void less than Rtype/PEG. Figure 10(d) shows the scattering layers of P25/R-type/PEG. We can find R-type and P25 titanium dioxide are evenly mixed. Even though the scattering layers have voided, which filled up with P25 titanium dioxide? The P25/R-type/PEG photoelectrodes is best structure of scattering layers. It is shown that this structure is due to multiple refraction of light. The structure is shown in Figure 11 which is schematic diagram of titanium dioxide scattering layer. SEM can observe that the polyethylene glycol-added scattering layer has more pore structures. These pores and irregular surface patterns enable more sunlight to be scattered in which improves the electrode's ability to capture sunlight.

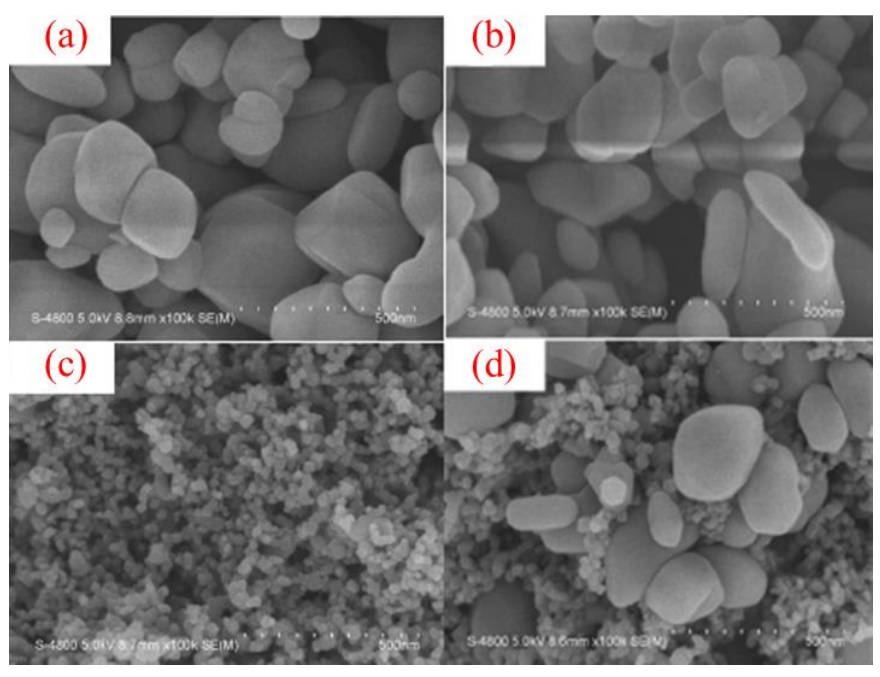

Figure 10. Scanning electron micrograph (SEM) of the scattering layers. (a)R-type (b)R-type/PEG (c) P25/PEG (d) P25/R-type/PEG. Magnification at $100 \mathrm{k}$.
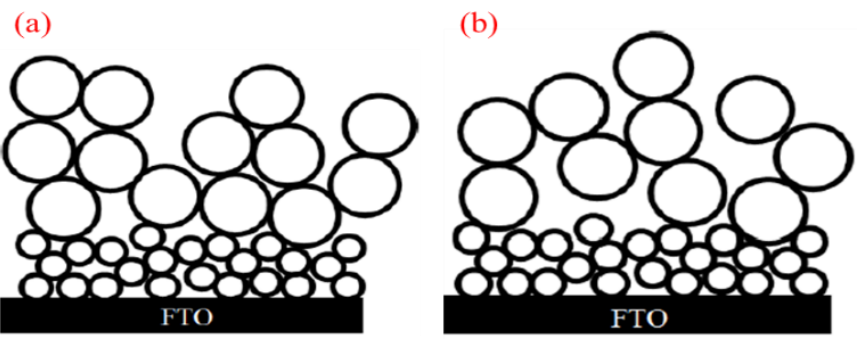

(c)
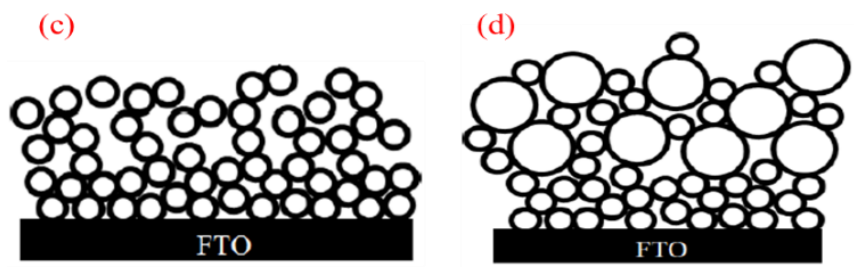

Figure 11. Diagram of different titanium dioxide scattering layers schemme. (a)R-type (b)R-type/PEG (c) P25/PEG (d) P25/R-type/PEG.

\subsection{I-V testing of photocells}

The TiO2-coated FTO glass substrates were thermally treated using supercritical carbon dioxide fluid synchronous dyeing method in this study. In the experiment, natural dyes were used to extract anthocyanins and chlorophylls, and supercritical carbon dioxide fluid was used to dye natural dyesensitized solar cells. Electrochemical instruments test different extraction and dyeing conditions to obtain the best conversion efficiency parameters. From the experimental results, we can obtain natural dyes with a conversion efficiency of $0.05^{\sim} 0.07 \%$ on anthocyanins and chlorophyll natural dyes with a conversion efficiency of $0.04 \sim 0.08 \%$ in Figure 12 .

The use of supercritical carbon dioxide fluid extraction and simultaneous dyeing is compared with traditional solvent extraction dyeing. The latter takes 105 minutes, but the former can achieve the same effect in only 30 minutes, and there is no problem of organic solvent pollution. It can be clearly seen that the use of supercritical fluid as a medium can significantly shorten the material extraction and dyeing time. In this experiment, the effect of placing the scattering layer is obvious. The main reason is that supercritical carbon dioxide fluid has the 
characteristics of low surface tension, low viscosity and high diffusivity, so it can be easily removed from plants and to achieve the purpose of dyeing.
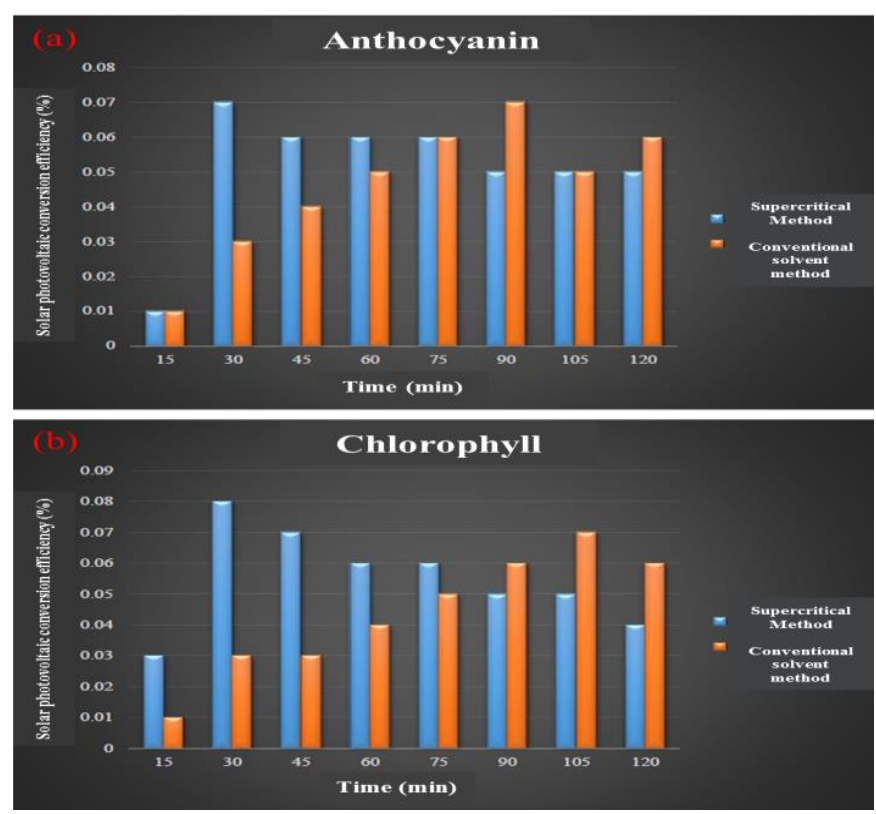

Figure 12. Effect of dyeing time on solar photoelectric

conversion efficiency by solvent method and supercritical method. (a) anthocyanin (b)chlorophyll

In order to increase the availability of dye-sensitized solar cells, this study also considered cocktail dyes mixed with anthocyanins and chlorophyll to improve the thermal stability of natural dyes. Table 2 shows roselle and red phoenix as the cocktail dye mixing codes used in the experiment. The 9:1 cocktail dye of anthocyanin and chlorophyll showed the best conversion efficiency of $0.13 \%$ in Figure 13 . Because the thermal stability of chlorophyll is worse than that of anthocyanin, anthocyanin is used as a protective agent to improve the conversion efficiency.

Supercritical carbon dioxide fluid synchronous dyeing procedure is used at the pressure 3000 psi with 30 minutes. The anthocyanin reaches the best photoelectric conversion efficiency of $0.10 \%$ and the chlorophyll is $0.08 \%$. The cocktail dye mixed with anthocyanin and chlorophyll by weight ratio of 9:1 can effectively improve the photoelectric conversion efficiency of the battery to $0.13 \%$ by supercritical fluid treatment at $50{ }^{\circ} \mathrm{C}$, which is improved by $62.5 \%$ and $55.6 \%$ compared with anthocyanin and chlorophyll dyes. And after improvement, the light half-decay test can reach about 3.6 hours, shown on Figure 14. Experimental results show that the use of cocktail dyes can effectively improve the photoelectric conversion efficiency of the battery and has better stability of descent. Figure 15 shows that decline curve of conversion efficiency with different layers. We can find R-type and R-type/PEG scattering photoelectric conversion efficiency curve are even lower than that of pure dye adsorption layer. Because R-type and R-type/PEG scattering layers affected by rutile titanium dioxide that can't achieve good electron transport. P25 /R-type/PEG scattering layer showed good photoelectric conversion efficiency at the initial stage because the R-type was homogeneously mixed with P25 titanium dioxide in the scattering layer and had good contact to produce similar synergistic effect. That is meaning that it becomes necessary to include a light scattering layer such that the lower photon conversion due to compact layer could be compensated. [7,19] In this experiment, the effect of placing the scattering layer is obvious. Finally the paper proposes a schematic diagram of the dye-sensitized solar cell, as shown in figure 16.

Table 2. Cocktail dyestuff mixed code

\begin{tabular}{|c|c|c|}
\hline \multirow{2}{*}{$\begin{array}{c}\text { Cocktail } \\
\text { dyestuff mixed }\end{array}$} & \multicolumn{2}{|c|}{ Dye weight ratio } \\
\cline { 2 - 3 } & Chlorophyll & Anthocyanin \\
\hline CA91 & 9 & 1 \\
\hline CA73 & 7 & 3 \\
\hline CA55 & 5 & 5 \\
\hline CA37 & 3 & 7 \\
\hline CA19 & 1 & 9 \\
\hline
\end{tabular}




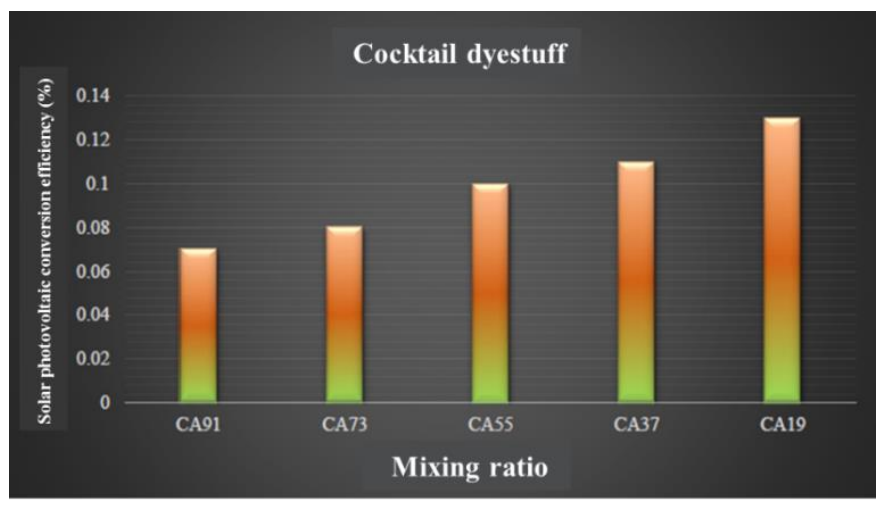

Figure 13. The conversion efficiency of cocktail dyestuff mixed by supercritical carbon dioxide fluid synchronous dyeing.

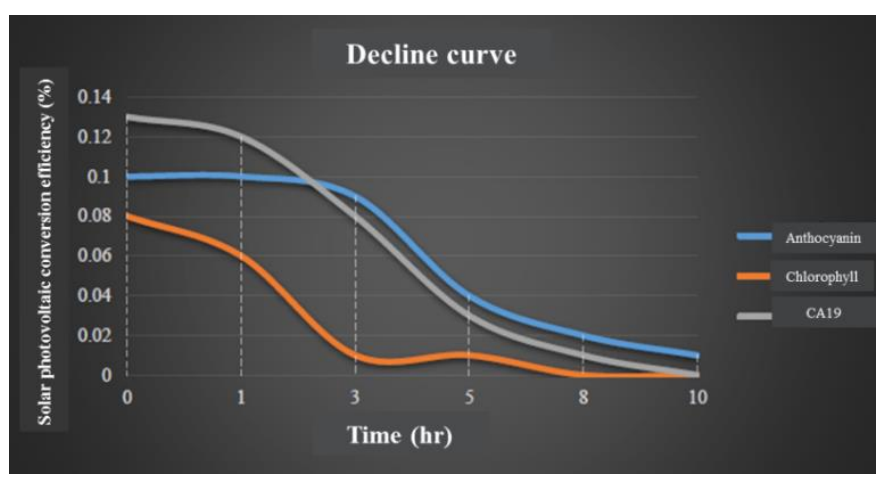

Figure 14. The decline curve of conversion efficiency at anthocyanin, chlorophyll and cocktail CA19

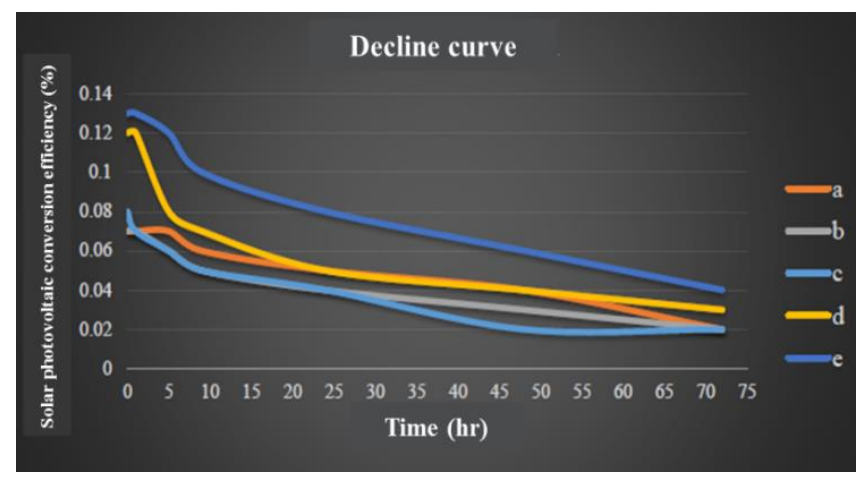

Figure 15. The decline curve of conversion efficiency

(a) compact layer, and 4 kinds of scattering layer (b) R-type (c) R-type/PEG (d) P25/PEG (e) P25/Rtype/PEG

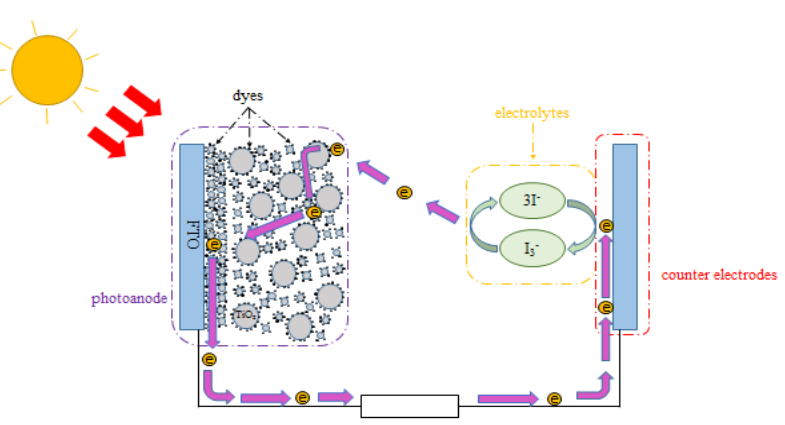

Figure 16. Model of schematic diagram on dye sensitized solar cells

\section{CONCLUSION}

Dye-sensitized solar cells (DSSCs) belong to the group of thin-film solar cells which have been under extensive research for more than three decades due to their low cost, simple preparation methodology, low toxicity and ease of production. In conclusion, DSSCs offers an efficient and easily implemented technology for future energy supply. Compared to conventional silicon solar cells, it provides comparable the photoelectric conversion efficiency at low material and manufacturing costs. This Paper study provided the experimental evidence that supercritical carbon dioxide fluid synchronous dyeing enhances cocktail dyes mixed with anthocyanins and chlorophyll to improve the thermal stability of DSSCs. The supercritical mechanism is a green environmental indicator. Using its high density and high diffusivity to make dye-sensitized solar cells can effectively shorten the manufacturing process and achieve high efficiency dyes. The extraction and the photoelectrode are dyed simultaneously to reduce the interference of external factors, thereby improving the photoelectric conversion efficiency of the battery. Compared with the traditional solvent method, the use of supercritical carbon dioxide fluid to extract the dye and the simultaneous dyeing of the photoelectrode reduces the manufacturing process while the battery still maintains the original or even better photoelectric conversion efficiency. At the same time, SEM can observe that the polyethylene 
glycol-added scattering layer has more pore structures. These pores and irregular surface patterns enable more sunlight to be scattered, which improves the electrode's ability to capture sunlight. Effectively improve the photoelectric conversion efficiency of the battery. Finally, the paper proposes a schematic diagram of the dye-sensitized solar cell including compact layer and scattering layer.

\section{ACKNOWLEDGMENT}

The authors are grateful to the National Science Council in Taiwan for financial support.

\section{REFERENCES}

[1]. GiuseppeCalogero, Gaetano DiMarco., (2008) Red Sicilian orange and purple eggplant fruits as natural sensitizers for dye-sensitized solar cells, Sol. Energy Mater. Sol. Cells, Vol.92, 1341-1346.

https://doi.org/10.1016/j.solmat.2008.05.007

[2]. Shen-Kung Liao,Yuan-Hsu Chang,Chung-Tse Wu,Yan-Rong Lai,Wei-Yu Chen., ( 2017) Fabrication of anthocyanin-sensitized nanocrystalline titanium dioxide solar cells using supercritical carbon dioxide, Journal of CO2 Utilization, Vol.21, 513-520. DOI: 10.1016/j.jcou.2017.07.006

[3]. Jiawei Gong, K.Sumathy, Qiquan Qiao, Zhengping Zhou., (2017) Review on dyesensitized solar cells (DSSCs): Advanced techniques and research trends, Renewable and Sustainable Energy Reviews, Vol.68(1), 234246. https://doi.org/10.1016/j.rser.2016.09.097

[4]. Tsubomura, H., Matsumura, M., Nomura, Y., Amamiya, T., ( 1976) Dye sensitized zinc oxide/aqueous electrolyte/platinum photocell, Nature, Vol. 261, p.402-403. https://www.nature.com/articles/261402a0

[5]. Grätzel M., O'Regan B., (1991) A low-cost, high-efficiency solar cell based on dye- sensitized colloidal TiO2 films, Nature, Vol. 353 ,

737-740.

https://www.nature.com/articles/353737a0

[6]. Judy N. Hart, David Menzies, Yi-Bing Cheng, George P., Simon, Leone Spiccia., (2006) TiO2 sol-gel blocking layers for dye-sensitized solar cells, Comptes Rendus Chimie, Vol. 9(5-6), 622-626.

https://doi.org/10.1016/j.crci.2005.02.052

[7]. Hore S., Vetter C., Kern R., Smit H., Hinsch A.,(2006) Influence of scattering layers on efficiency of dye-sensitized solar cells, Solar Energy Materials \& Solar Cells, Vol.90(9), 1176-1188. DOI:10.1016/j.solmat.2005.07.002

[8]. Jinho Chae, Dong Young Kim, Sujung Kim, Misook Kang., (2010) Photovoltaic efficiency on dye-sensitized solar cells (DSSC) assembled using Ga-incorporated TiO2 materials, Journal of Industrial and Engineering Chemistry, Vol.16(6),

906-911. DOI:10.1016/j.jiec.2010.09.012

[9]. Niu Huang, Yumin Liu, Tao Peng, Xiaohua Sun, Bobby Sebo, Qidong Tai, Hao Hu, Bolei Chen, Shi-shang Guo, Xingzhong Zhao., (2012) Synergistic effects of $\mathrm{ZnO}$ compact layer and TiCl4 post-treatment for dye-sensitized solar cells, Journal of Power Sources, Vol.204, 257264. DOI:10.1016/j.jpowsour.2011.12.027

[10]. Curtiss S. Kovash Jr., James D. Hoefelmeyer, Brian A. Logue., (2012) TiO2 compact layers prepared by low temperature colloidal synthesis and deposition for high performance dyesensitized solar cells, Electrochimica Acta, Vol.67, 18-23. DOI:10.1016/j.electacta.2012.01.092

[11]. R. Marr and T. Gamse., (2000) Use of Supercritical Fluids for Different Processes Including New Developments: A Review, Chemical Engineering and Processing, Vol.39(1), 19-28. DOI:10.1016/S02552701(99)00070-7 
[12]. W. H. Hauthal., (2001) Advances with Supercritical Fluids (Review), Chemosphere, Vol. 43(1), 123-135. DOI:10.1016/S00456535(00)00332-5

[13]. Shen-kung Liao \& Chang Pi-Shiun., ( 2012) Literatures on Dyeing Technique of Supercritical Fluid Carbon Dioxide" American Journal of Analytical Chemistry, Vol.3(12A),923-930. DOI: 10.4236/ajac.2012.312A122

[14]. Giuseppe Calogero, Gaetano Di Marco, (2008) Red Sicilian orange and purple eggplant fruits as natural sensitizers for dye-sensitized solar cells, Solar Energy Materials \& Solar Cells, Vol.92(11), 1341-1346. https://doi.org/10.1016/j.solmat.2008.05.007

[15]. Jung-Kun Lee, Mengji Yang, (2011) Progress in light harvesting and charge injection of dyesensitized solar cells, Materials Science and Engineering, Vol.176(15), 1142-1160. DOI:10.1016/j.mseb.2011.06.018

[16]. Xiao-Feng Wang, Yasushi Koyama, Osamu Kitao, Yuji Wada, Shin-ich Sasaki, Hitoshi Tamiaki, Haoshen Zhou.,(2010) Significant enhancement in the power-conversion efficiency of chlorophyll co-sensitized solar cells by mimicking the principles of natural photosynthetic light-harvesting complexes, Biosensors and Bioelectronics, Vol.25(8), 19701976. https://doi.org/10.1016/j.bios.2010.01.015

[17]. T.S.Senthil, N.Muthukumarasamy, Dhayalan Velauthapillai, S.Agilan, M.Thambidurai, R.Balasundaraprabhu.,(2011) Natural dye (cyanidin 3-O-glucoside) sensitized nanocrystalline $\mathrm{TiO} 2$ solar cell fabricated using liquid electrolyte/quasi-solid-state polymer electrolyte, Renewable Energy, Vol.36(9), 2484-2488. DOI:10.1016/j.renene.2011.01.031

[18]. P. Sanjay, K. Deepa, J. Madhavan, S. Senthil.,(2018) Fabrication of DSSC with Nanostructured TiO2 Photoanode and Natural Dye Sensitizer extracted from fruits of
Phyllanthus reticulatus, International Journal of Scientific Research in Scienceand Technology, Vol.4(5), 437-443. https://www.academia.edu/37117740/

[19]. Khushboo Sharma, Vinay Sharma, S. S. Sharma., (2018) Dye-Sensitized Solar Cells: Fundamentals and Current Status, Nanoscale Research Letters, Vol.13, 381-427. https://doi.org/10.1186/s11671-018-2760-6

\section{Cite this article as :}

Shen-Kung Liao, Jin-yu Ruan, Chih-Hsun Liao, "Efficiency Improvement in Dye-Sensitized Solar Cells by Modify Titanium Dioxide Formation on Supercritical Carbon Dioxide Fluid Synchronous Dyeing", International Journal of Scientific Research in Science and Technology (IJSRST), Online ISSN : 2395-602X, Print ISSN : 2395-6011, Volume 8 Issue 4, pp. 626-636, July-August 2021. Available at doi : https://doi.org/10.32628/IJSRST218497 Journal URL : https://ijsrst.com/IJSRST218497 